\title{
Development and Implementation of Computer Assisted Instruction System in Physical Education Based on ASP.NET Technology
}

\author{
https://doi.org/10.3991/ijet.v14i13.10712 \\ Jing Yang $\left.{ }^{(}\right)$, Zhen Zhao \\ Beijing Institute of Petrochemical Technology, Beijing, China \\ yangjing@bipt.edu. on
}

\begin{abstract}
Due to the practicalness of physical education (PE) teaching, the computer-assisted instruction (CAI) in PE can deepen students' understanding through visual teaching methods. The purpose of this paper is to study the development and implementation of CAI system in PE. To this end, based on hardware such as campus network and internet, B/S/D three-layer system was adopted in this paper as the system architecture, and ASP.NET technology was used to realize system functions. The research results show that the system is divided into four parts: the teaching resource module, the online Q\&A module, the coursework module and the exam module according to the system requirements analysis. Then, taking the system login, teacher module and system test module as examples, the system operation process was designed in detail to achieve its specific functions. This re-search enriches the theoretical and practical research results of CAI system in PE and promotes the reform of physical education teaching mode.
\end{abstract}

Keywords-ASP.NET, computer-assisted instruction (CAI) system, physical education (PE), development and implementation

\section{Introduction}

The rapid development of computer technology, Internet technology and network technology has brought about fundamental changes in the teaching model, breaking the limitations of traditional teaching in time and space, and enhance the communication between teachers and students and between students [1]. Physical education (PE) is a highly practical and typical bilateral teaching activity [2]. Through visualized teaching methods, students' understanding can be deepened. Therefore, in order to adapt to more advanced PE training and teaching, more and more research scholars conduct research on network and CAI system in PE.

More cases of using network and CAI system in PE can be retrieved at home and abroad. The development of foreign computer and network technology has taken a long time. As early as the mid-1980s, colleges and universities in the United States strongly advocated computer-assisted instruction (CAI) and have been committed to network development [3]. At present, the United States has made great achievements 
in the system function, theoretical basis and production process construction of the PE multimedia network teaching platform, playing a leading role in the world [4]. The UK attaches great importance to the development of multimedia PE network teaching; teachers and students can make full use of the rich teaching resources on the network by means of multimedia teaching, and realize online and offline communication, thus improving students' enthusiasm and teaching effect [5]. In recent years, China's research on CAI system in PE has also made great progress. Zhang Wei of Daqing Petroleum Institute pointed out the inevitability of the network education model in physical education curriculum [6]; Wang Lijun et al. through study on network situation in PE teaching, considered that CAI has the characteristics of interaction and individuality in the network environment [7]; Xu Yu carried out research on the quality management standards of PE network courses [8]; Han Ming explored the development and implementation of the CAI system in PE and proposed effective solutions [9]. Thus, it's found that although the theoretical basis of CAI system in PE in China's network environment is relatively sufficient, the computer-assisted instruction in physical education courses of many colleges and universities are still lagging behind [10]. ASP.NET is a general-language-based program architecture developed by Microsoft Corporation, which can simplify the development of dynamic Web pages for CAI system in PE [11].

Through the above analysis, this paper briefly introduces ASP.NET technology, and selects the $\mathrm{B} / \mathrm{S} / \mathrm{D}$ three-layer system as the system architecture after the comparative analysis of $\mathrm{C} / \mathrm{S}$ and $\mathrm{B} / \mathrm{S}$ structure. Based on system user requirements and functional requirements analysis, the system is divided into: teaching resource module, online Q\&A module, coursework module and exam module, and the functions of each module are also introduced in detail. Then, taking the system login, teacher module and system test module as examples, the detailed design of the system operation process is carried out to realize its specific functions.

\section{Relevant Theory of System Design}

\subsection{System mode selection}

C/S structure: The $\mathrm{C} / \mathrm{S}$ structure consists of two parts: client and server. It is a two-tier architecture mode, Figure 1 shows the $\mathrm{C} / \mathrm{S}$ bilayer architecture. The task of the client is to provide the user request to the server program, while the server receives the request from the client program and then returns it to the client program after processing [12]. 


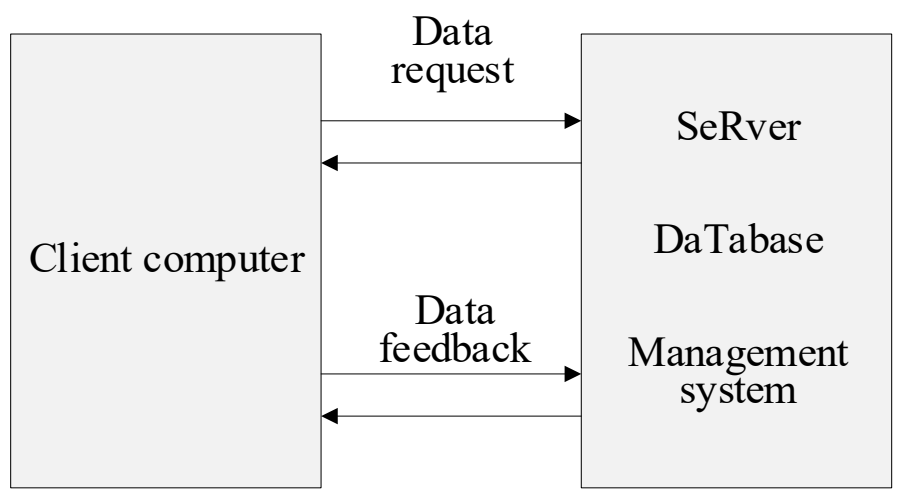

Fig. 1. C/S double layer architecture diagram

B/S structure: The $\mathrm{C} / \mathrm{S}$ structural mode has the problems such as the poor scalability, low pro-cessing efficiency with the large number of computers, large postmaintenance work-load, and high cost. In order to solve these problems, there appears the $\mathrm{B} / \mathrm{S}$ structure mode, that is, add new application server between the database and the database serve to form a three-layer structure [13]. Figure 2 shows the three-layer structure of the $\mathrm{B} / \mathrm{S}$ structure.

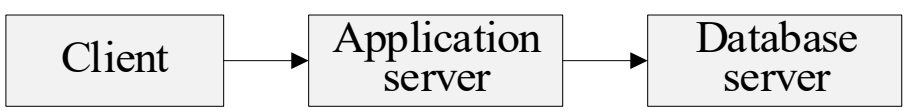

Fig. 2. Schematic diagram of three-layer structure based on $\mathrm{B} / \mathrm{S}$ structure

System mode selection: In this paper, the three-layer structure mode consisting of Browser/Web Server/DBMS Server was selected to develop a computer-assisted instruction system in physical education, which has the advantages of simple use, good extensibility and easy maintenance [14]. Figure 3 shows the structure of the three-layer structure mode of Browser/Web Server/DBMS Server. The teacher saves the relevant $\mathrm{PE}$ teaching resources and learning materials to the relevant homepage through the server side of the database. After receiving the user's request, the web server retrieves the corresponding content in the database through ODBC and feeds back to the user. Thus, only by a computer connected to network, the students can learn by accessing the web server of the CAI system, and also realize online discussion and query functions etc. 


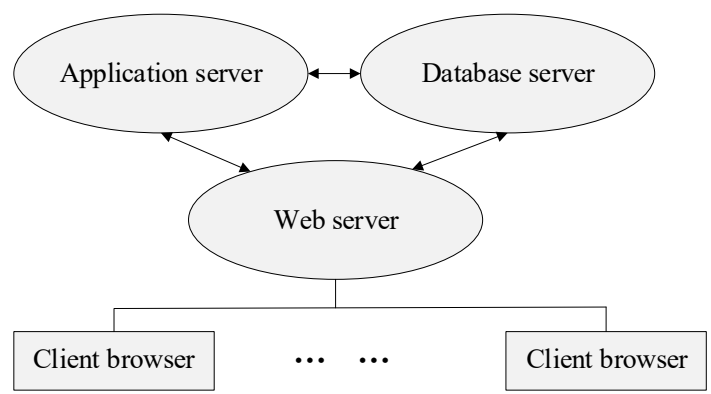

Fig. 3. Structure diagram of the three-layer structure mode of Browser/Web Server/DBMS Server

\subsection{ASP.NET technology}

Interactivity is the focus of CAI system in PE, so it becomes critical to build dynamic web pages [15]. ASP.NET technology is the general-language-based program architecture developed by Microsoft Corporation. Compared with the existing development model, ASP.NET technology has more powerful support tools. It has great advantages in simple server operating environment, great adaptability, customization and scalability, easy operation, and high execution efficiency, which simplifies the development of dynamic Web pages. In addition, ASP.NET provides built-in objects such as Request, Response, Page, Serve, etc., meeting the need for page information carrier and specific state management [16]. Therefore, ASP.NET technology was selected as the environment for system application development in this paper. Figure 4 shows the structure of the .NET Framework.

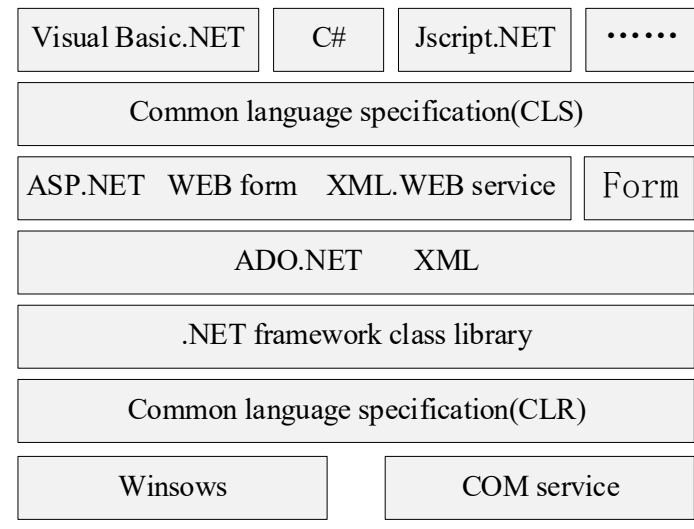

Fig. 4. NET framework architecture 


\section{Development and Implementation of Computer-Assisted Instruction in Physical Education Based on ASP.NET Technology}

\subsection{System requirements analysis}

User requirements analysis: The design of CAI system in PE should follow the principle of informatization, highlight the teaching objectives and teaching content, fully embody the importance of the situation in the learning process, highlight the student's dominant position, and focus on the collaborative learning environment. In the end, it can achieve the purpose of improving the students' interest in learning, facilitating the communication between teachers and students and between students, and enabling teachers to master their learning situation, and timely adjusting the curriculum plan and teaching methods.

Functional requirements analysis: According to the user requirements analysis of the system, the system should meet the following functions, as shown in Figure 5:

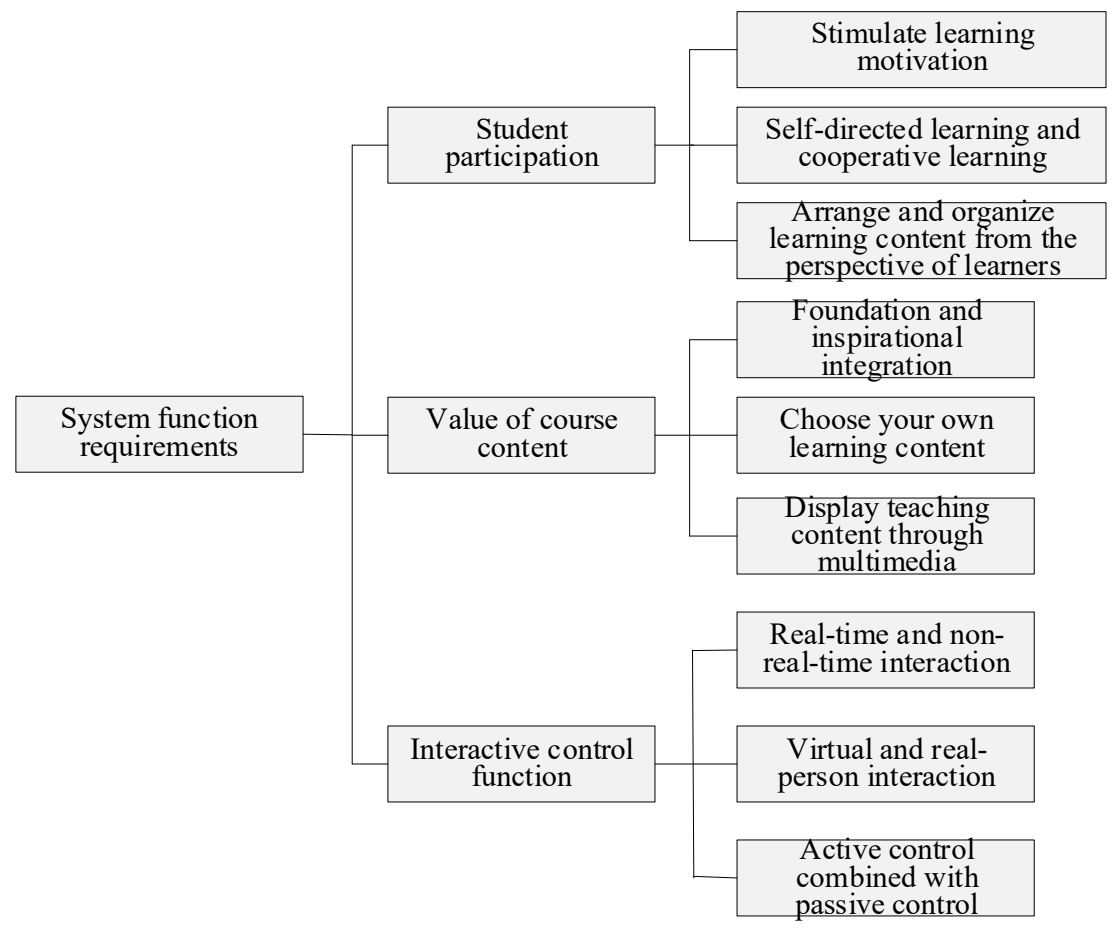

Fig. 5. System function requirement map

- To ensure the students' participation in system design, it's necessary to first motivate the learner's motivation, then realize the organic combination of independent 
learning and cooperative learning, and finally arrange and organize the learning content from the perspective of learners.

- The course content of CAI system in PE system must meet the needs of value, the choice of teaching content should focus on the combination of fundamentality and enlightenment, so that learners can choose their own learning content according to their own situation and the teaching content can be presented to learners through the multimedia methods such as audio, video, graphics, etc.

- The system should meet the requirements of real-time interaction and non-realtime interaction, virtual human interaction and real-human interaction, active control and passive control.

\subsection{Overall system design}

System architecture design: The function of the CAI system in PE based on ASP.NET technology is realized through the exchange of the user's browser and the application server. Administrators, teachers, and students can make requests to the server through a browser installed on the computer, while the server retrieves database information based on user requests and then feeds the results back to the user, Figure 6 shows a schematic diagram of a computer-aided physical education system.

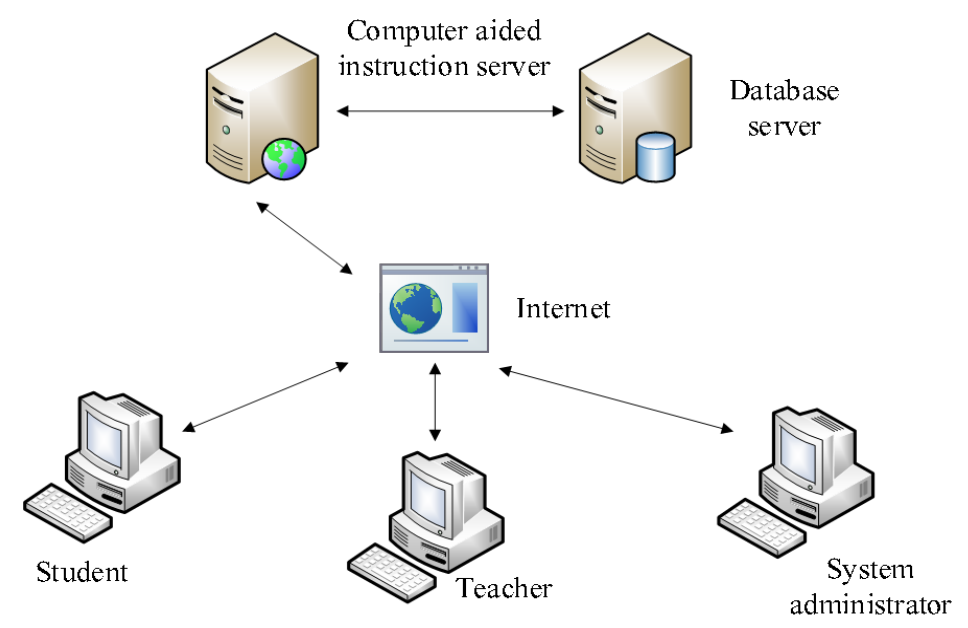

Fig. 6. Schematic diagram of computer-aided physical education teaching system

System function module design: Based on the analysis of system user requirements and functional requirements, the CAI system in PE system is divided into four modules: teaching resource module, online Q\&A module, coursework module and exam module [17], as shown in Figure 7.

Teaching resource module: Through the teaching resource module, students can browse and inquire about teaching plan, introduction to teachers of different professions, syllabus, PE teaching program and other teaching resources at any time. 
Online $Q \& A$ module: The online Q\&A module is the main module for realizing teacher-student interaction. The module includes three sub-modules: BBS, online Q\&A, and physical exercise advice. Students can use this module to communicate with teachers and students in real time for problems in learning, while the teachers can give advance for physical exercise to students based on the student's physical exercise advice module.

Coursework module: The coursework module includes theoretical work and practical homework. The teacher can use this module to manage the student's classroom work and homework assignments. The submodule of theoretical work is based on the teaching syllabus and plan, including the knowledge and technical action essentials in each PE class, which is convenient for students to view at any time; the submodule of the practical homework is to specify the specific methods and number of exercises mainly for the knowledge required for the PE theory class, helping students master the content they have learned.

Examination module: Teachers can upload relevant test scoring standards through this module. Students conduct theoretical tests through this module; teachers give score, and also publish the test scores through this module for students' inquiry.

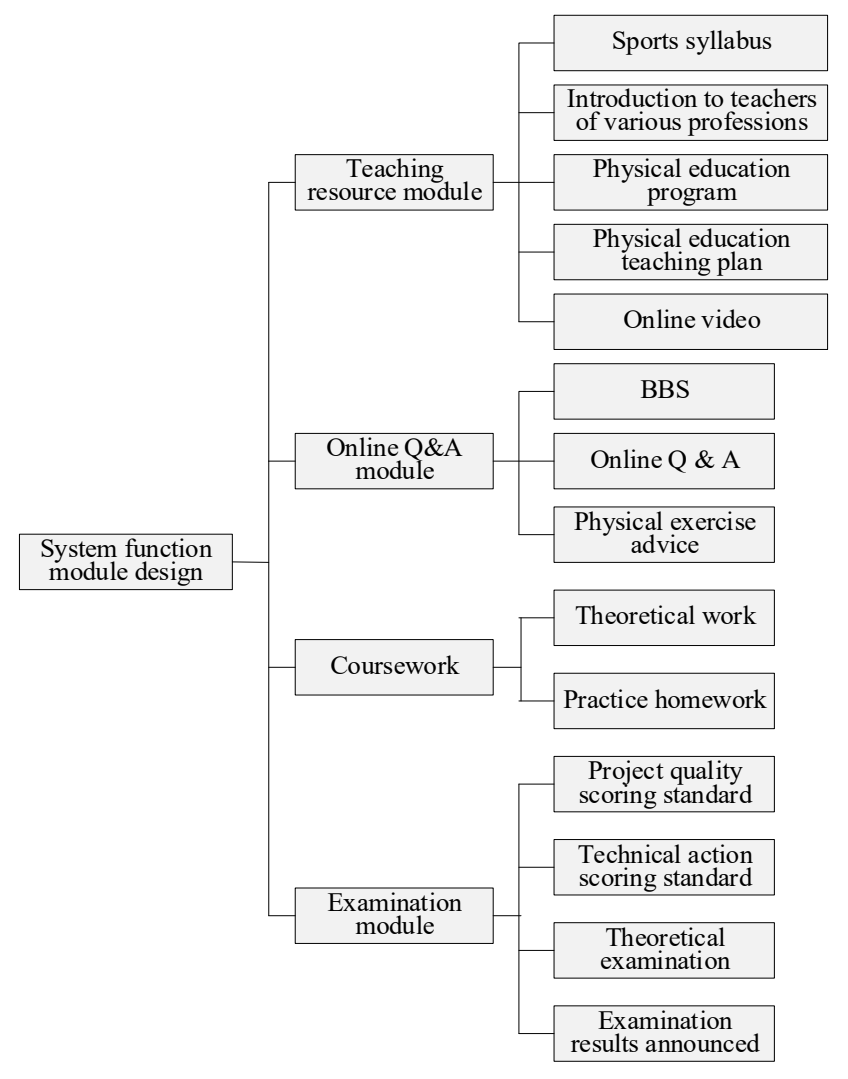

Fig. 7. System function module design 


\subsection{Detailed design and implementation of the system}

User login interface design and implementation: System users include three categories: administrator, teacher, and student. No matter which type of user, they need to register for the first time. Each time one enters the system interface, they cannot enter the system directly. Whereas, they need to enter the relevant account name and password and pass the verification before you can log in to the system interface under the related authority, Figure 8 shows the system login process, and Figure 9 shows the system login interface.

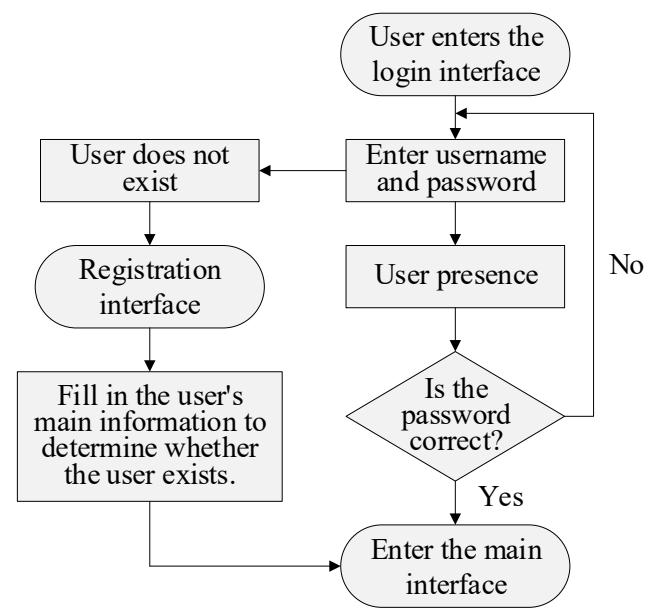

Fig. 8. System login process

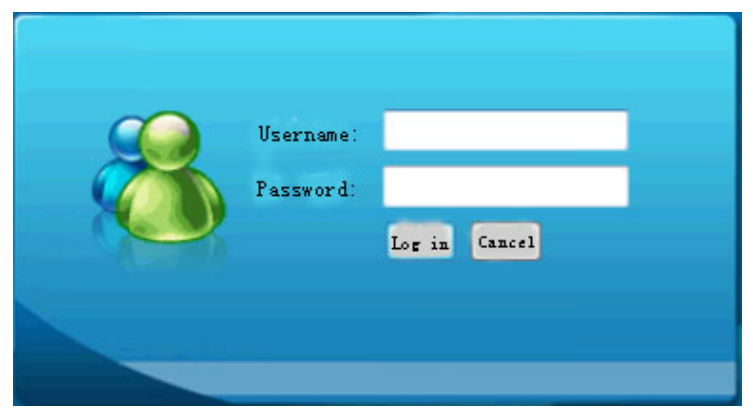

Fig. 9. User login interface

Detailed design and implementation of the teacher application module: Teachers can access the teacher application module through the computer to manage the course, courseware and homework by the operations of viewing, adding, deleting, and modifying, etc. Figure 10 shows the function of the teacher management system of the CAI system in PE system, Figure 11 shows the teacher adding the teaching content interface. 


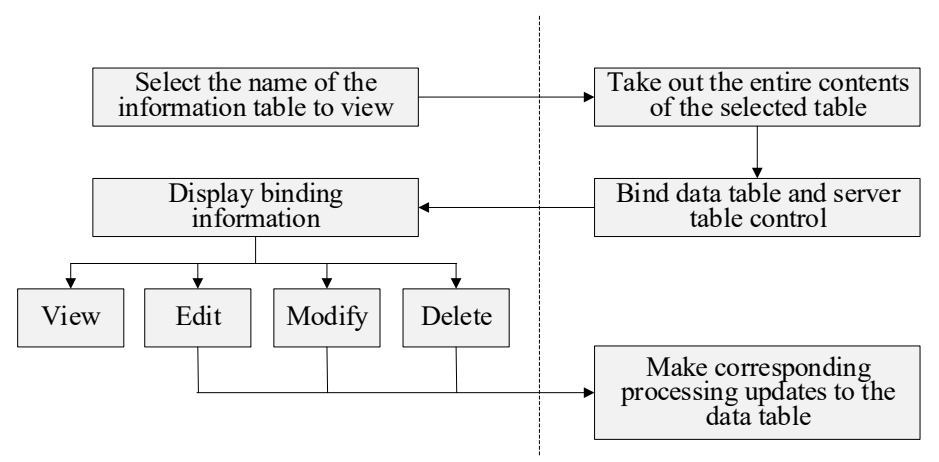

Fig. 10.System teacher management system function diagram

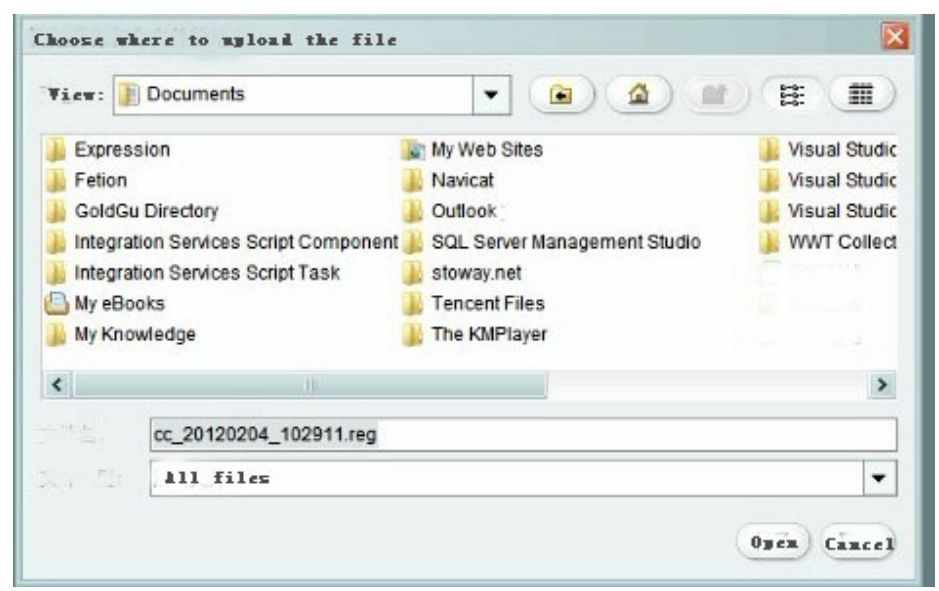

Fig. 11. Teacher added teaching content interface

Detailed design and implementation of the PE examination module: Different from other courses, PE is a very practical subject. Therefore, the examination form of PE is divided into two parts: theoretical examination and practical examination. For practical examinations, students can systematically check relevant standards of technical movements and project quality scores. Besides, mastering certain PE theory knowledge is also one of the PE teaching objectives stipulated in the PE syllabus. Therefore, the system has also designed the theoretical examination module in detail.

The teacher uploads the exam questions through the teacher management interface. Figure 12 shows the interface where the teacher can add to the exam questions. After entering the correct user name and password, students can conduct the exam in the PE theory exam module. The exam questions are randomly assigned by the system. Students should complete the answer within the specified time, and the system will make auto prompting five minutes earlier. The system will automatically submit the exam paper when time is up, so that students cannot view it again. After the exam, the system will automatically display the students' exam scores and list of wrong questions. Figure 13 shows the flow chart of the PE theory exam. 


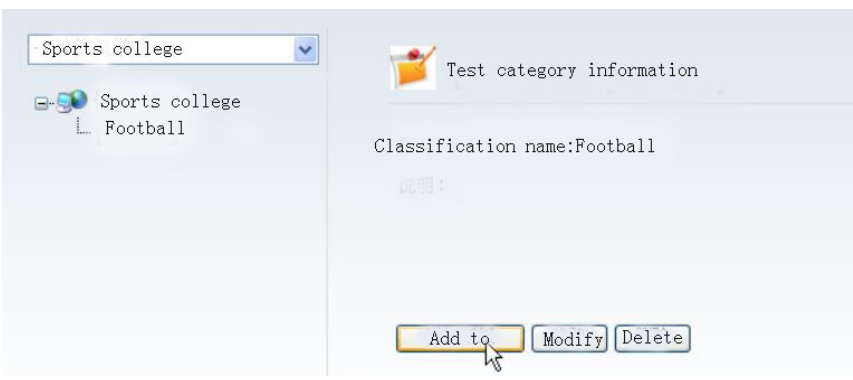

Fig. 12. Test management interface

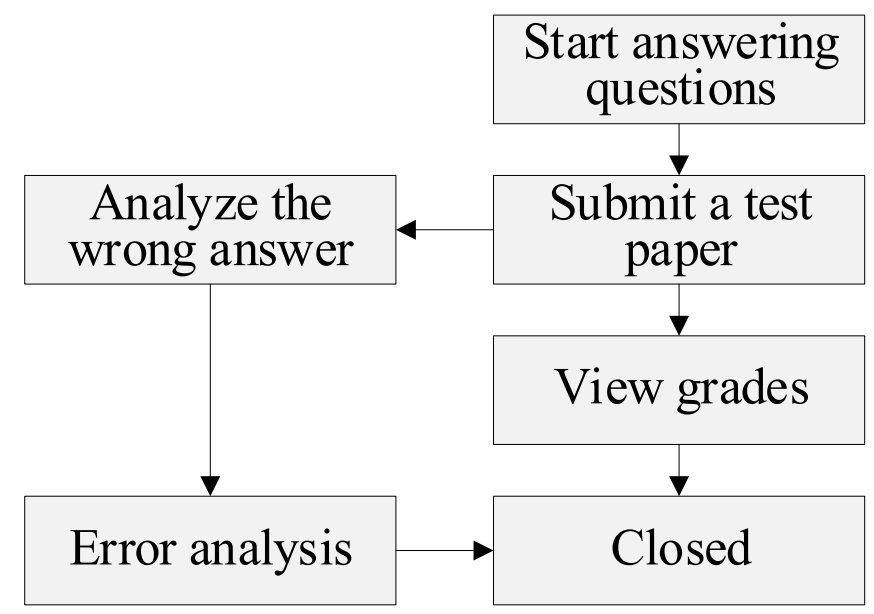

Fig. 13.Sports theory test flow chart

\section{Conclusion}

Based on the hardware of campus network and internet etc., this paper studies the development and implementation of CAI system in PE system. The specific conclusions are as follows:

Through the comparative analysis of $\mathrm{C} / \mathrm{S}$ and $\mathrm{B} / \mathrm{S}$ structure modes, the $\mathrm{B} / \mathrm{S} / \mathrm{D}$ three-tier system was finally selected as the system architecture;

Based on the analysis of system user requirements and functional requirements, the system is divided into four modules: teaching resource module, online Q\&A module, coursework module and exam module, and the functions of each sub-module were introduced in detail;

Taking the system login, teacher module and system test module as examples, the detailed design of the system operation process was conducted, and ASP.NET technology was adopted to realize various functions of the system. 


\section{$5 \quad$ References}

[1] Xia, Y., Cambria, E., Hussain, A. (2015). Aspnet: aspect extraction by bootstrapping generalization and propagation using an aspect network. Cognitive Computation, 7(2): 241253. https://doi.org/10.1007/s12559-014-9305-9

[2] Karac1, A., Arıc1, N. (2014). Determining students' level of page viewing in intelligent tutorial systems with artificial neural network. Neural Computing \& Applications, 24(3-4): 675-684. https://doi.org/10.1007/s00521-012-1284-8

[3] Sun, L., Liu, M., Hu, J., Liang, X. (2014). A Chinese character teaching system using structure theory and morphing technology. Plos One, 9(6): e100987. https://doi.org/10.1371/journal.pone.0100987

[4] Ward, P., Lee, M.A. (2005). Peer-assisted learning in physical education: a review of theory and research. Journal of Teaching in Physical Education, 24(3): 205-225. https://doi.org/10.1123/itpe.24.3.205

[5] Perlman, D. (2010). Change in affect and needs satisfaction for amotivated students within the sport education model. Journal of Teaching in Physical Education, 29(4): 433-445. https://doi.org/10.1123/jtpe.29.4.433

[6] Hastie, P.A. (1994). Selected teacher behaviors and student alt-pe in secondary school physical education. Journal of Teaching in Physical Education, 13(3): 242-259. https://doi.org/10.1123/jtpe.13.3.242

[7] Chen, C.H., Wu, I.C. (2012). The interplay between cognitive and motivational variables in a supportive online learning system for secondary physical education. Computers \& Education, 58(1): 542-550. https://doi.org/10.1016/j.compedu.2011.09.012

[8] Martin, J.J., Kulinna, P.H. (2005). A social cognitive perspective of physical activity related behavior in physical education. Journal of Teaching in Physical Education, 24(3): 265281. https://doi.org/10.1123/jtpe.24.3.265

[9] Eynur, B.R. (2015). A survey of the attitudes of dumlupinar university physical education vocational college and faculty of education students on computer-assisted education (CAE). Anthropologist, 20(1-2): 340-352. https://doi.org/10.1080/09720073.2015.1189 $\underline{1738}$

[10] Jago, R., Mcmurray, R.G., Bassin, S., Pyle, L., Bruecker, S., Jakicic, J.M. (2009). Modifying middle school physical education: piloting strategies to increase physical activity. Paediatric Exercise Science, 21(2): 171-185. https://doi.org/ 10.1123/pes.21.2.171

[11] Papastergiou, M. (2009). Exploring the potential of computer and video games for health and physical education: a literature review. Computers \& Education, 53(3): 603-622. https://doi.org/10.1016/j.compedu.2009.04.001

[12] Rasberry, C.N., Lee, S.M., Robin, L., Laris, B.A., Russell, L.A., Coyle, K.K. (2011). The association between school-based physical activity, including physical education, and academic performance: a systematic review of the literature. Preventive Medicine, 52: S10S20. https://doi.org/10.1016/j.ypmed.2011.01.027

[13] Kirk, D., Macdonald, D. (1998). Situated learning in physical education. Journal of Teaching in Physical Education, 17(3): 376-387. https://doi.org/10.1123/jtpe.17.3.376

[14] Stolow, R.D., Joncas, L.J. (1980). Computer-assisted teaching of organic synthesis. Journal of Chemical Education, 57(12): 868-876. https://doi.org/10.1021/ed057p868

[15] Casey, A., Goodyear, V.A. (2015). Can cooperative learning achieve the four learning outcomes of physical education? a review of literature. Quest, 67(1): 56-72. https://doi.org/10.1080/00336297.2014.984733 
[16] Mihal, A., Kulkarni, C., Moskewicz, M., Tsai, M., Shah, N., Weber, S. (2002). Developing architectural platforms: a disciplined approach. IEEE Design \& Test of Computers, 19(6): 6-16. https://doi.org/10.1109/mdt.2002.1047739

[17] Gibb, G., Lockwood, J.W., Naous, J., Hartke, P., Mckeown, N. (2008). Netfpga-an open platform for teaching how to build gigabit-rate network switches and routers. IEEE Transactions on Education, 51(3): 364-369. https://doi.org/10.1109/te.2008.919664

\section{Authors}

Jing Yang graduated from Beijing sports university in 2001, received his bachelor's degree in physical education, and she graduated from Beijing normal university sports institute in 2010, have a master's degree in sports. She worked currently in Beijing institute of petrochemical industry, and mainly engaged in sports teaching, training and research title lecturer. In 2014, she was funded by the young talents project of Beijing municipal education commission, and in 2018, she won the second prize of the 19th sports science paper report conference of capital universities.

Zhen Zhao graduated from capital institute of physical education in 2002, received his bachelor's degree in sports training, and graduated from Liaoning normal university sports institute in 2010, have a master's degree in sports. He worked currently in Beijing institute of petrochemical industry, and mainly engaged in sports teaching, training and research title lecturer. In 2017, he edited and published the "guidance course for college students' extracurricular sports activities", and won the second prize in the 19th sports science paper report conference of capital universities in 2018.

Article submitted 2019-04-17. Resubmitted 2019-05-26. Final acceptance 2019-05-27. Final version published as submitted by the authors. 